\title{
Konjenital adrenal hiperplazi
}

Dilek BİNGÖL AYDIN ${ }^{1}$, Engin AYDIN² ${ }^{2}$ Turan YILDIZ ${ }^{3}$, Ş. Pınar İŞGÜVEN ${ }^{4}$

\begin{tabular}{lr}
\hline $\begin{array}{l}\text { Öz } \\
\text { Bu görüntülü olgu sunumunda şüpheli genitalya ile başvuran 21-hidroksilaz eksikliğine } \\
\text { bağl1 konjenital adrenal hiperplazili 8 aylık bir bebek sunulmaktadır. }\end{array}$ & $\begin{array}{r}\text { Yayın Bilgisi } \\
\text { Gönderi Tarihi:04.12.2017 } \\
\text { Kabul Tarihi:04.04.2018 }\end{array}$ \\
Anahtar Kelimeler: Genitalya, 21-hidroksilaz, konjenital adrenal hiperplazi, bebek & $\begin{array}{r}\text { Online Yayın Tarihi:30.06.2018 } \\
\text { DOI: 10.26453/otjhs.360874 }\end{array}$ \\
Sorumlu Yazar \\
Dilek BİNGÖL AYDIN
\end{tabular}

\section{Congenital Adrenal Hyperplasia}

Dilek BİNGÖL AYDIN ${ }^{1}$, Engin AYDIN² ${ }^{2}$ Turan YILDIZ ${ }^{3}$, Ş. Pınar İşGÜVEN ${ }^{4}$

Abstract
In this illustrated case report, 8 month old baby with congenital adrenal hyperplasia (21-
hydroxylase deficiency) who was presented with ambiguous genitalia was described.

Keywords: : Genitalia, 21-hydroxylase, congenital adrenal hyperplasia, baby
Article Info

Received:04.12.2017

Accepted:04.04.2018

Online Published:30.06.2018

DOI: $10.26453 /$ otjhs. 360874

Corresponding Author

Dilek BİNGÖL AYDIN

\footnotetext{
${ }^{1}$ Sakarya Üniversitesi Tıp Fakültesi Pediatri AD, Sakarya

${ }^{2}$ Sakarya Üniversitesi Tıp Fakültesi Pediatri AD, Sakarya

${ }^{3}$ İnönü Üniversitesi Tıp Fakültesi Çocuk Cerrahi AD, Malatya

${ }^{4}$ Sakarya Üniversitesi Tıp Fakültesi Çocuk Endokrinoloji BD, Sakarya
}

\section{GíRiș}

Sekiz aylık kız olarak yetiştirilmiş bebek şüpheli genital yapı nedeni ile ailesi tarafından Çocuk Cerrahi Polikliniğine başvurmuş ve oradan Çocuk Endokrin Polikliniğine yönlendirilmişti. Burada yapılan değerlendirmede; boyu $68 \mathrm{~cm}$ (25-50p), kilosu 7,5kg (10$25 p)$ idi. Anne ve babası ikinci dereceden akraba idi ve benzer kardeş öyküsü yoktu. Genel durumu iyi, genitoüriner sistem dışındaki sistem muayeneleri doğaldı. Sistolik ve diastolik kan basınçları yaşa göre normal sınırlar içinde idi Hastanın yapılan genital muayenesinde fallus hipertrofisi olduğu (fallus boyu $2 \mathrm{~cm}$ ) görüldü. Üretra orifisi fallus tabanına açılmakta idi ancak vajina orifisi görülemedi. Genital katlantılar içinde gonad benzeri yapılar ele gelmedi (Resim 1). Yapılan kan tetkiklerinde glukoz $87 \mathrm{mg} / \mathrm{dL}$, üre $6 \mathrm{mg} / \mathrm{dL}$, kreatinin 0,44 $\mathrm{mg} / \mathrm{dL}$, ürik asit 4,1 $\mathrm{mg} / \mathrm{dL}$, sodyum $135 \mathrm{mmol} / \mathrm{L}$, potasyum $5,9 \mathrm{mmol} / \mathrm{dL}$ (yüksek), klor $105 \mathrm{mmol} / \mathrm{L}$, ALP $362 \mathrm{U} / \mathrm{L}$, AST $35 \mathrm{U} / \mathrm{L}$, ALT $38 \mathrm{U} / \mathrm{L}$, kalsiyum 10,3 mg/dL, fosfor 5,6 $\mathrm{mg} / \mathrm{dL}$, magnezyum 2,24 mg/dL CRP 0,32 idi. Pelvik ultrasonda uterus 25x10 mm boyutunda, bilateral overler normal idi. 
Hormonal değerlendirmede; 17 hidroksi progesteron 2000 ng/dL (yüksek), 1,4 deltaandrostenedion $2,5 \mathrm{ng} / \mathrm{mL}$ (yüksek), serbest testosteron 0.72 , total testosteron $29.65, \mathrm{FSH}$ 2,81 mUI/mL, LH 0,53 mUI/mL, kortizol 2,5 $\mu \mathrm{g} / \mathrm{dL}$, progesteron 10,9 $\mathrm{ng} / \mathrm{mL}$, estradiol $<10$ pg/dL, DEAH-SO4 98,4 $\mu \mathrm{g} / \mathrm{dL}$ idi. Karyotipi 46XX olarak değerlendirildi.

$\mathrm{Bu}$ hasta için tanınız nedir?

(Yanıt İçin Tıklayınız)

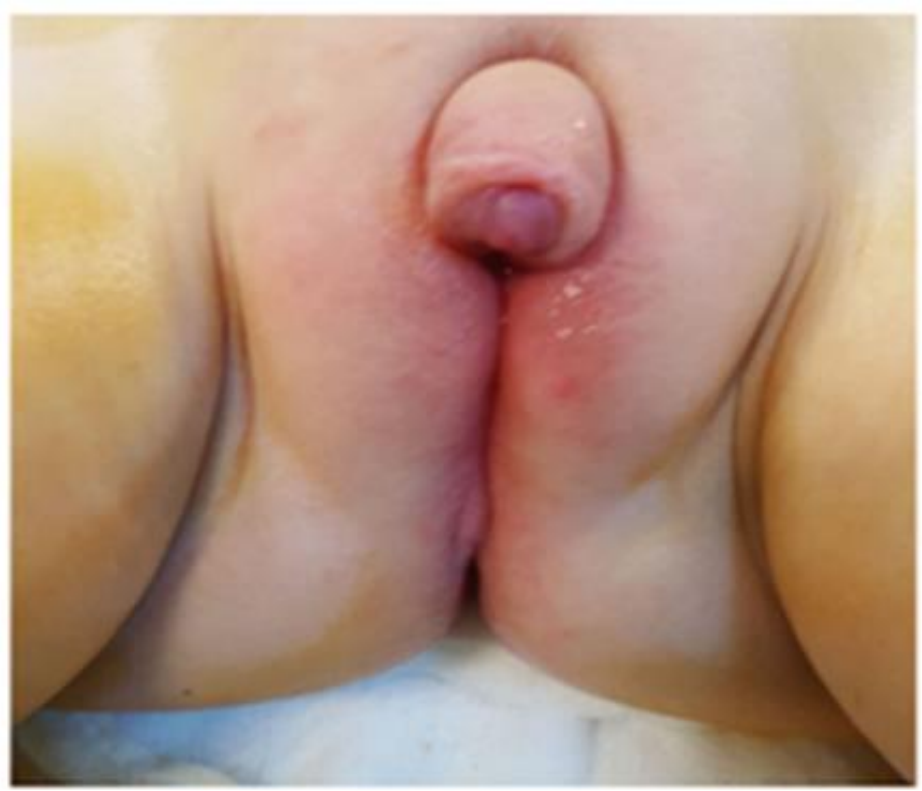

(Yanıt İçin Tıklayınız) 


\section{YANIT}

Konjenital Adrenal Hiperplazi (KAH) adrenal steroid biyosentezini etkileyen bir hastalıktır. En s1k görülen tipi 21 hidroksilaz eksikliğidir (\% 90-95). Enzim eksikliğinin derecesine göre klinik tablo değişkenlik gösterir. Hastalığın klinik olarak klasik ve klasik olmayan olmak üzere iki tipi vardır. Bizim vakamız, cinsel gelişim bozukluğu saptandığı için klasik tip KAH olarak değerlendirildiğinden ilerleyen paragrafta klasik KAH'ın özelliklerinden bahsedilecektir. KAH; CYP21A2 geninde mutasyon ile ortaya çıkan, yaklaşık 1-10000 115000 doğumda bir görülen otozomal resesif olarak kalıtılan bir hastalıktır. ${ }^{1} \mathrm{KAH}$, birçok ülkede yenidoğan tarama programında 17- hidroksiprogesteron düzeyi ile taranmaktadır. Ülkemizde ise 2017 yılında pilot program ile üç ilde taranmaya başlanmıştır.

Hastalık ilk defa 1865 'de tanımlanmıştır. Ana problem antenatal çağdan itibaren adrenal kortekslerde kolesterolden yapılan steroid sentezinin bozulması nedeniyle glukokortikoid, mineralokortikoid ve androjenlerin salgısında bozukluk olmasıdır. ${ }^{2} 21$ hidroksilaz eksikliğinde yolaktaki dönüşüm androjenler (androstenedion, dehidroepiandrostenedion ve testosteron) yönüne kayarak kız çocuklarda virilizasyona neden olabilir. Klasik KAH'da 21 hidroksilaz enziminin tamamen eksikliğinde; ölümcül adrenal yetmezlik ve tuz kaybı krizi oluşur. 21 hidroksilaz enzim eksikliğinde yenidoğan kız bebeklerde virilizasyon ve ambigious genitalya görülerken, erkek bebekte hiperpigmentasyon ve fallus büyüklüğü dışında bir bulgu yoktur ve tuz kaybı ölümcül tek belirti olabilir. Hastalarda serum 17- hidroksiprogesteron seviyesinde artış görülür (N: <100 ng/dL) ve klasik KAH olgularında bu yükseklik tanı için yeterlidir. Hafif vakalarda kortikotropin stimülasyon testi ile yine 17- hidroksiprogesteron düzeyi bakılabilir. Virilize kız infantlarda glukokortikoid ve tuz kaybı eşlik ediyorsa mineralokortikoid replasmanı hızlıca yapılmalıdır. Hastaların iç genital yapıları kromozomal yapılarına uygundur ve tedavi edilen kız çocukların üreme potansiyelleri vardır. Dış genital yapının şüpheli olduğu olgularda cinsiyet seçimine kromozomal ve anatomik yapıya göre karar verilmelidir. Erken tanı konan 46 XX bebeklerin kız yönünde yetiştirilmeleri uygundur. Ayrıca bu hastaların ilerleyen yaşlarda cinsiyet eğilim bozuklukları gösterdikleri de bilinmektedir. Opere edilen virilize kız çocuklarında vajinal stenoz çok sık görülen bir rekonstriksiyon komplikasyonudur. Ayrıca kliteroplasti yapılan hastalarda klitoral ağrı görülebilmektedir. ${ }^{3-5}$ 


\section{KAYNAKLAR}

1-El-Maouche D, Arlt W, Merke DP. Congenital adrenal hyperplasia. Lancet. 2017;390(10108):2194-2210. doi: 10.1016/S0140-6736(17)31431-9.

2-Nimkarn S, Lin-Su K, New MI. Steroid 21 hydroxylase deficiency congenital adrenal hyperplasia. Pediatr Clin North Am. 2011;58(5):1281-300. doi: 10.1016/j.pcl.2011.07.012.

3-Witchel SF, Azziz R. Congenital adrenal hyperplasia. J Pediatr Adolesc Gynecol. 2011;24(3):116-26.

4-Wang LC, Poppas DP. Surgical outcomes and complications of reconstructive surgery in the female congenital adrenal hyperplasia patient: What every endocrinologist should know. $\mathrm{J}$ Steroid Biochem Mol Biol. 2017;165(Pt A):137-144.

5-Trapp CM, Speiser PW, Oberfield SE. Congenital adrenal hyperplasia: an update in children. Current Opinion in Endocrinology, Diabetes, and Obesity. 2011;18(3):166-170. 